\title{
$L C L$ filter design for grid-connected single-phase flyback microinverter: a step by step guide
}

\author{
Muhamad Faizal Yaakub ${ }^{1}$, Mohd Amran Mohd Radzi², Maaspaliza Azri ${ }^{3}$, Faridah Hanim Mohd Noh \\ ${ }^{1}$ Fakulti Teknologi Kejuruteraan Elektrik dan Elektronik, Universiti Teknikal Malaysia Melaka, Malaysia \\ ${ }^{1,2}$ Faculty of Engineering, Universiti Putra Malaysia, Malaysia \\ ${ }^{3}$ Fakulti Kejuruteraan Elektrik, Universiti Teknikal Malaysia Melaka, Malaysia \\ ${ }^{4}$ Faculty of Engineering Technology, Universiti Tun Hussein Onn Malaysia, Malaysia \\ ${ }^{1,2}$ Advanced Lightning, Power and Energy Research Centre, Universiti Putra Malaysia
}

\section{Article Info}

Article history:

Received Jun 7, 2021

Revised Jul 12, 2021

Accepted Auf 11, 2021

\section{Keywords:}

LCL filter

Grid connected

Flyback microinverter

\begin{abstract}
Recently, $L C L$ has become amongst the most attractive filter used for gridconnected flyback inverters. Nonetheless, the switching of power devices in the inverter configuration creates harmonics that affect the end application behavior and might shorten its lifetime. Furthermore, the resonance frequencies produced by the $L C L$ network contribute to the system instability. This paper proposes a step-by-step guide to designing an $L C L$ filter by considering several key aspects such as the resonance frequency and maximum current ripple. A single-phase grid-connected flyback microinverter with an $L C L$ filter was designed then constructed in the MATLAB/Simulink environment. Several different parameter variations and damping solutions were used to analyze the performance of the circuit. The simulation result shows a promising total harmonic distortion (THD) value below $5 \%$ and harmonic suppression up to $14 \%$.
\end{abstract}

This is an open access article under the CC BY-SA license.

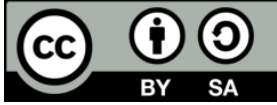

\section{Corresponding Author:}

Muhamad Faizal Yaakub

Faculty of Engineering

Universiti Putra Malaysia

Serdang, Selangor, Malaysia

Email: muhamadfaizal@utem.edu.my

\section{INTRODUCTION}

In recent decades, the demand for energy has escalated exponentially driven by the growing population and increasing wealth across the globe. Hence, green energy harvested from an inexhaustible source such as solar, wind, and tide have attracted enormous attention [1], [2]. Since the distributed power generation systems became mainstream, grid-connected microinverters turned to be a research hotspot. In most cases, the grid-connected microinverter is controlled by a pulse width modulation (PWM) switching technique which generates harmonics and requires a low pass filter to eliminate the unwanted high-frequency signals from getting through into the distribution system. Numerous approaches of low pass filters have been proposed and implemented such as $L-, L C$-, and $L C L$-filter. Among these topologies, the $L C L$ - type has shown tremendous attenuation of harmonic suppression compared to others[3]. Unfortunately, the physical filter, as shown in Figure 1, is impossible to be constructed using the theoretically calculated values. Therefore, several parameters have to be reconsidered, especially in regards to the inductance and capacitance value that vary due to numerous factors such as components aging. 


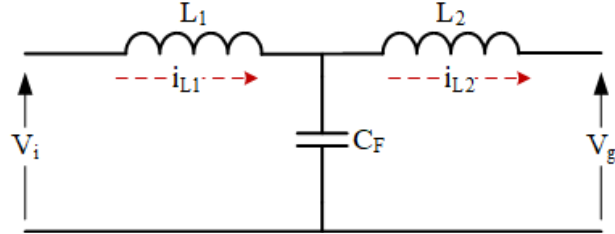

(a)

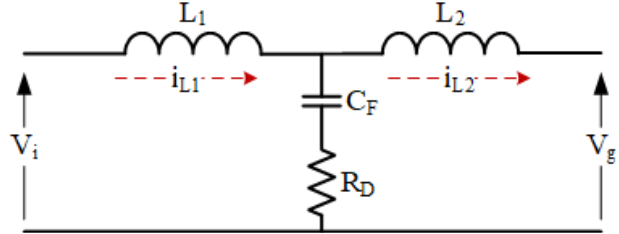

(b)

Figure 1: $L C L$ filter (a) without damping resistor and (b) with a damping resistor

Since the grid side inductor $L_{2}$ of a filter is connected in series to the grid, the inductive impedance of a long grid cable and low power transformers may have influenced parameter variation in $L_{2}$. Additionally, the inductance may also be varied with its rate values up to $75 \%$ due to the core's magnetic permeability on a current flowing in the network [4]. The capacitance tolerance is in the range of $\pm 5 \%$ to $\pm 20 \%$, depending on their dielectric properties. These variations cause resonance frequency shifting and subsequently resulting in instability to the control system and the filter behavior. A great number of works have been carried out to deal with the resonance and instability such as the passive damping approach [5]-[7], active damping method [8]-[10], and even dampingless method [4], [11] to achieve the stability criterion based on various types of control techniques. Nonetheless, there is very limited literature that elaborates a clear step-by-step guide to choose appropriate passive element values for the filter, especially of the open-loop type. This paper presents the stepwise design procedure of an open-loop LCL filter for a grid-tied microinverter [12], [13]. The proposed design steps are based on the current ripple minimization approach. It is extremely important to regulate the output current and voltage with the ripple value as minimum as possible which complies with the value set by the standards [14], [15]. In a nutshell, this paper contributes to a simple and organized step of designing the $L C L$ filter. Only the essential mathematical equation for the initial theoretical calculation with numerical design examples are presented. The equations and the usage are stated in the design flowchart. An improvised design flow with an additional resonance check-loop and parameter compliance test is proposed in this paper. The key parameters obtained from the theoretical calculation and parameter compliance test were simulated in the Simulink platform and the results are discussed.

The paper is organized as follows; the filter's essential parameters used in the design are described and presented in Section 2, together with the corresponding mathematical equations. The design flow/steps, numerical design example, and value selection rationality are vividly explained in Section 3. Subsequently, simulation results are extensively discussed in Section 4, including the effect on parameter variation to emulate real scenario conditions. Finally, a conclusion is provided at the end of the article.

\section{THE FILTER DESIGN}

\subsection{Current ripple}

The high-frequency current ripple attenuation of the filter is primarily influenced by the $L C$ part. The inductance plays a significant role in controlling the current ripple and suppresses the low-frequency harmonics spectrum [5], [16]. As such, the inductor has to be properly designed by considering the allowable current ripple tolerance. The peak-to-peak current ripple of one particular filter for the unipolar PWM inverter can be calculated based on Equation (1). The magnitude distribution is illustrated in Figure 2 wherein the value is varied depending on the current phase and the modulation index.

$$
\Delta i_{p p}(\omega t)=\frac{V_{i}}{2 L f_{s w}}\left(1-m_{x} \sin \omega t\right) m_{x} \sin \omega t
$$

with $V_{i}$ is the input DC voltage, $L$ is the inductance, $f_{s w}$ is the switching frequency, and $m_{x}$ is the modulation index. The maximum fluctuation, $\beta_{c} I_{1}$, of the $L_{l}$ current appears when $\sin \omega_{o} t=1 /\left(2 m_{x}\right)$, and defined as

$$
\beta_{c} I_{1}=\frac{V_{i}}{8 L_{1} f_{s w}}
$$




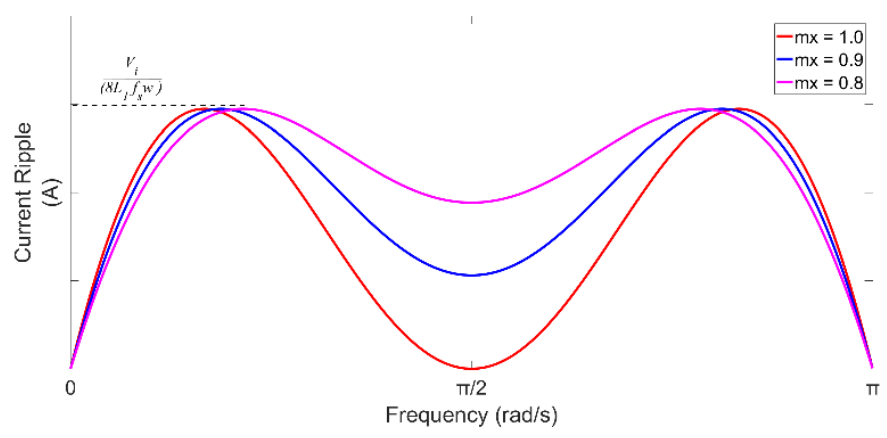

Figure 2: Current ripple magnitude distribution

where $L_{l}$ is the inverter's grid side inductance, $I_{l}$ is the rated current, and $\beta_{c}$ is the inductor current ripple coefficient which is defined as $I_{r p m a x} / I_{l}$. Typically, $\beta_{c}$ is set in the range of 5\% to 30\% [5], [17]-[20] and with some parameters substitution, the inductor maximum current ripple is expressed as:

$$
I_{\text {rpmax }}=\frac{V_{i}}{8 L_{1} f_{s w}}
$$

Although the main objective is to produce a smaller ripple current, a smaller ripple current will lead to slower power device switching during conduction. Subsequently, it would increase the inductor size and generate higher core losses [21]. These are the challenges and trades off to be decided upon designing the filter.

\subsection{Inverter Side Inductance}

The inductance of the $L C L$ filter is crucial and imposes a significant impact on the harmonic suppression and current ripple control. It limits the current ripple produced by the inverter switching. At a particular switching frequency, the voltage-current ratio is traceable only by the inverter inductance. During switching time $T_{s w}$, the inverter average voltage is considered constant whenever the fundamental frequency is way too small compared to the switching frequency. The minimum inverter side inductance value is obtained from (1), (2), and (3) using a simple mathematical manipulation with an assumption that the grid system is stiff and has a unity power factor,

$$
L_{1 \_\min }=\frac{V_{i} T_{S W}}{8 I_{\text {rpmax }}}
$$

\subsection{Capacitor}

The harmonics which can negatively affect the system can be suppressed using a capacitor at the grid section of the $L C L$ filter. However, from a control system point of view, the capacitor provides a different behavioral influence depending on where the voltage and current are being measured [6], [22]-[24]. Here, during the design process, the capacitor's voltage is measured and the grid current is controlled as illustrated in Figure 3. The selection is made by the fact that the filter is integrated into the inverter system with dedicated current/voltage sensors and the control strategy that is used for the flyback-based converter. The maximum capacitance value can be calculated using Equation (5) below;

$$
C_{f \max }=\frac{\alpha P_{o}}{\omega_{o} V_{o}^{2}}
$$

where $V_{o}$ is the rated output voltage, $P_{o}$ is the rated power in total, and $\omega_{o}$ is a grid angular frequency. While, $\alpha$ is the power ratio and $\alpha P_{o}$ is a quantity of reactive power absorbed by the filter which is typically less than $5 \%$ [5], [11], [18]. Equation (5), it can be seen that the reactive power absorption is directly proportional to the capacitance value, which means that the higher the capacitance, the more power is absorbed by the capacitor. This leads to a higher current demand from the inductor and switches causing a higher current ripple and lower filtering efficiency. Nevertheless, the value of the capacitor must not be too low as it will increase inductor size and increase the voltage drop across the inverter side inductor. 


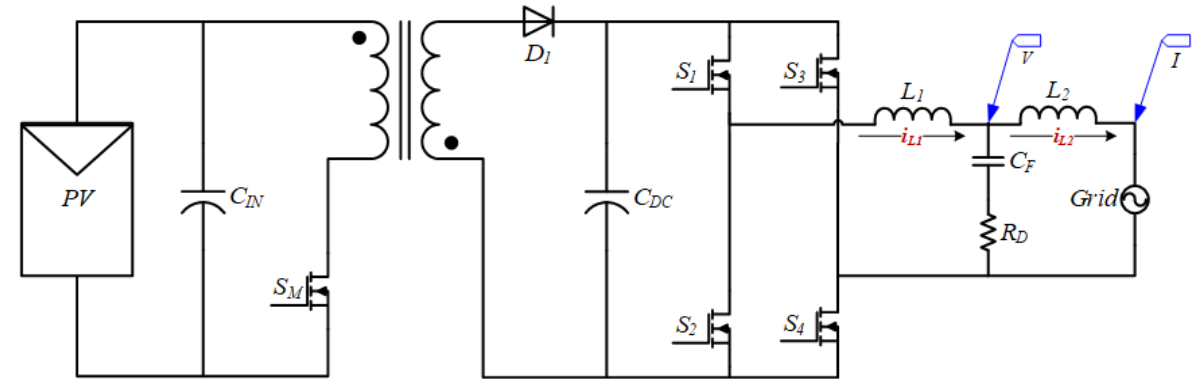

Figure 3: Voltage and current measurement at $L C L$ filter of a microinverter

\subsection{Grid Side Inductance}

The grid inductance affects the overall performance and effectiveness of the grid-side inductance of the $L C L$ filter. In most literature, the grid inductance factor is omitted from the transfer function and the resonance frequency derivation. This omission is acceptable in stiff grid circumstances, however, the grid inductance is always finite in distribution grids as reported in IEC 60725:2012 [4], [9], [25], [26]. A typical variation value of grid inductance is in the range of $\pm 20 \%$ [10], [14]. The grid inductance variation changes the resonance frequency. Having this in mind, the grid-side inductor $L_{2}$ has to be designed in such a way for the filter to be able to absorb any changes at grid-inductance value. The resonance frequency, $\omega_{\text {res }}$, of the filter by taking into account the grid inductance variation is defined in Equation (6) below;

$$
\omega_{\text {res }}=\sqrt{\frac{L_{1}+L_{2}+L_{g}}{L_{1}\left(L_{2}+L_{g}\right) C_{f}}}
$$

The resonance frequency, $\omega_{\text {res }}$, is directly related to the inductance ratio, $r$, which is dependent on the voltage and current sensor position at the filter. According to the position of the sensors as indicated in Figure 3, the resonance frequency, $\omega_{\text {res }}$, is given in Equation (7);

$$
\omega_{\text {res }}=\frac{z_{b}}{L_{1}} \sqrt{\frac{1+r}{r}}
$$

where $Z_{b}$ is the base impedance defined as $V_{o}^{2} / P_{o}$. To simplify the $L_{2}$ design, only stiff grid condition is considered, ignoring the grid inductance variation. Therefore, the angular resonance frequency, $\omega_{\text {res }}$, of the $L C L$ filter is finally expressed as;

$$
\omega_{\text {res }}=\sqrt{\frac{L_{1}+L_{2}}{L_{1} L_{2} C_{f}}}
$$

With the presence of a filter capacitor in the filter network, the grid-side inductance $L_{2}$ can be expressed with respect to the inductance ratio, $r$;

$$
L_{2}=r L_{1}
$$

The relationship between the resonance frequency and the inductance ratio $r$ is illustrated in Figure 4 . The resonance frequency of the $L C L$ filter must comply with the following constraint where it should be in the range between ten times of grid frequency and half of the switching frequency [1], [3], [5], [6], [11], [27], [28].

$$
10 f_{g} \leq f_{\text {res }} \leq 0.5 f_{\text {sw }}
$$




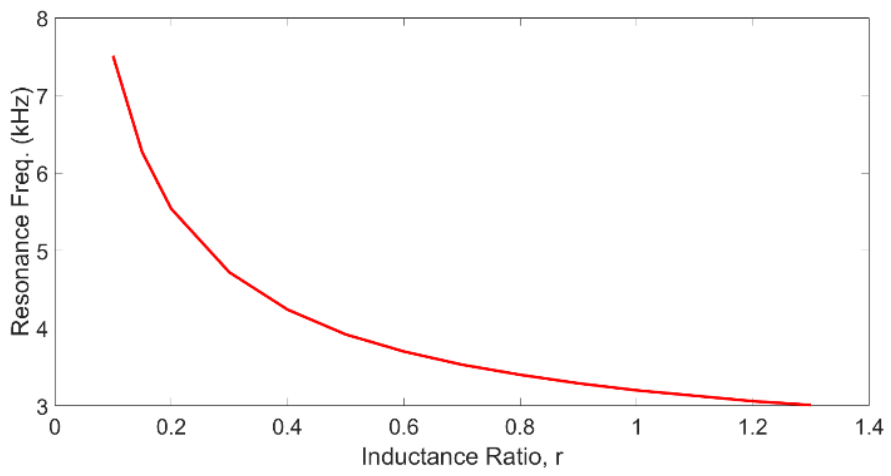

Figure 4: Resonance frequency, $\omega_{\text {res }}$, and inductance ratio, $r$, relationship generated from Equation (8)

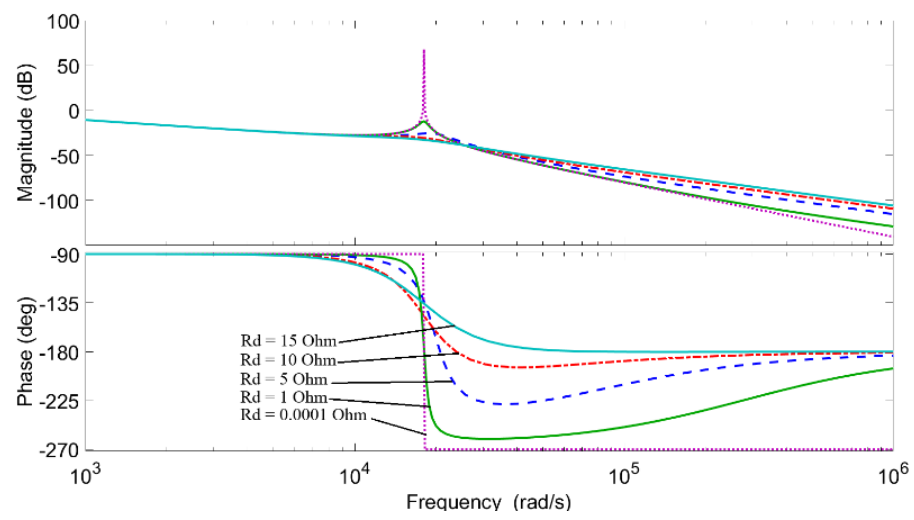

Figure 5: The impact of a dampening resistor, $R_{d}$, on the stability of a system

\subsection{Damping}

The $L C L$ filter will generate a resonance frequency that causes instability to the overall system. The effectiveness of the attenuation introduced by the $L C L$ filter will be achieved only if damping is properly implemented in the filter. Otherwise, an even higher current ripple will be introduced. This is a common issue reported in various literatures accompanied with the damping techniques used to rectify the problem [3], [5], [7], [10], [16], [22], [29], [30]. A passive damping method is chosen as it is widely adopted due to its ease of implementation. The method requires adding a resistor in series with the filter capacitance. Attention should be given to the resonance frequency, $\omega_{\text {res }}$, and sampling frequency to avoid high losses. Figure 5 illustrates the effect of various damping resistors values on the stability of the system given by the open-loop transfer function [31]. A higher damping resistor value yields a more stable system but one that suffers from higher losses. Therefore, an optimized damping resistor value must be considered to keep the balance between the system's stability and the losses reduction. Generally, the damping resistor of the $L C L$ filter is calculated by using the following equation which is one-third of the impedance of the filter capacitor [5].

$$
R_{d} \approx \frac{1}{3 \omega_{\text {res }} C_{f}}
$$

\section{DESIGN PROCEDURE AND EXAMPLE} Figure 6:

The $L C L$ filter design procedure is described according to the proposed design steps summarized in

i. The initial parameters of the system such as the rated power $(P)$, output voltage $\left(v_{o}\right)$, DC-link voltage $\left(v_{i}\right)$, system frequency $\left(f_{g}\right)$, switching frequency $\left(f_{s w}\right)$ are first to be defined. Table 1 summarizes the value of the variable of the system for the proposed design step. 
ii. For a wide ripple margin in the preliminary design calculation, the inductor current ripple coefficient, $\beta_{c}$ is selected as $30 \%$ and thus, gives the minimum inverter-side inductance $L_{1 \min }=1.68$ $\mathrm{mH}$. This is obtained using Equation (4). Finally, the nearest possible value $L_{l}=1.7 \mathrm{mH}$ is selected.

iii. The adopted power ratio, $\alpha=3 \%$, the anticipated quantity of reactive power absorbed by the filter is approximately 60 VAR. Substitution of the parameters' values to Equation (5) yields the maximum filter capacitance value, $C_{f \max }=3.95 \mu \mathrm{F}$. Therefore, $C_{f}=3 \mu \mathrm{F}$ is chosen considering the nearest offthe-shelf value and close to the maximum value as possible to ensure the small size of filter inductors.

iv. The value of the inductance ratio, $r$, is selected to comply with the resonance frequency condition. As for the economical point of view meant for future hardware development, $r=1$ is chosen at initial $f_{\text {res }}=3.2 \mathrm{kHz}$. Therefore, $L_{2}$ is set to be equal to $L_{1}=1.7 \mathrm{mH}$.

v. Using Equation (8), the resonance frequency is once more verified using selected values in steps $i i$, iii, and $i v$ to guarantee all chosen passive components parameters are complying with (10) since the values are slightly different from the preliminary calculation.

vi. Finally, the damping resistor is obtained from Equation (11) which is one-third of the impedance of the filter capacitor, yields $R_{d}=5 \Omega$.

vii. In a real case scenario, a variation compliance test is required to be performed to validate the performance and stability against the parameter variation that might occur. Minimum six test conditions are proposed for the test. Further elaboration is discussed in the later section.

Table 1. System parameters

\begin{tabular}{lccc}
\hline Parameter & Symbol & Value & Unit \\
\hline Rated output Power & $P_{o}$ & 2 & $\mathrm{~kW}$ \\
Grid voltage & $v_{o}$ & 220 & $\mathrm{~V}$ \\
DC-Link voltage & $v_{i}$ & 350 & $\mathrm{~V}$ \\
Grid frequency & $f_{g}$ & 50 & $\mathrm{~Hz}$ \\
Switching frequency & $f_{s w}$ & 10 & $\mathrm{kHz}$ \\
\hline
\end{tabular}

Table 2. Calculated filter parameters

\begin{tabular}{lccc}
\hline Parameter & Symbol & Value & Unit \\
\hline Inverter Side Inductance & $L_{l}$ & 1.7 & $\mathrm{mH}$ \\
Grid Side Inductance & $L_{2}$ & 1.7 & $\mathrm{mH}$ \\
Capacitor & $C_{f}$ & 3 & $\mu \mathrm{F}$ \\
Damping Resistor & $R_{d}$ & 5 & $\Omega$ \\
Inductance ratio & $r$ & 1 & \\
Resonance Frequency & $f_{\text {res }}$ & 3.2 & $\mathrm{kHz}$ \\
\hline
\end{tabular}

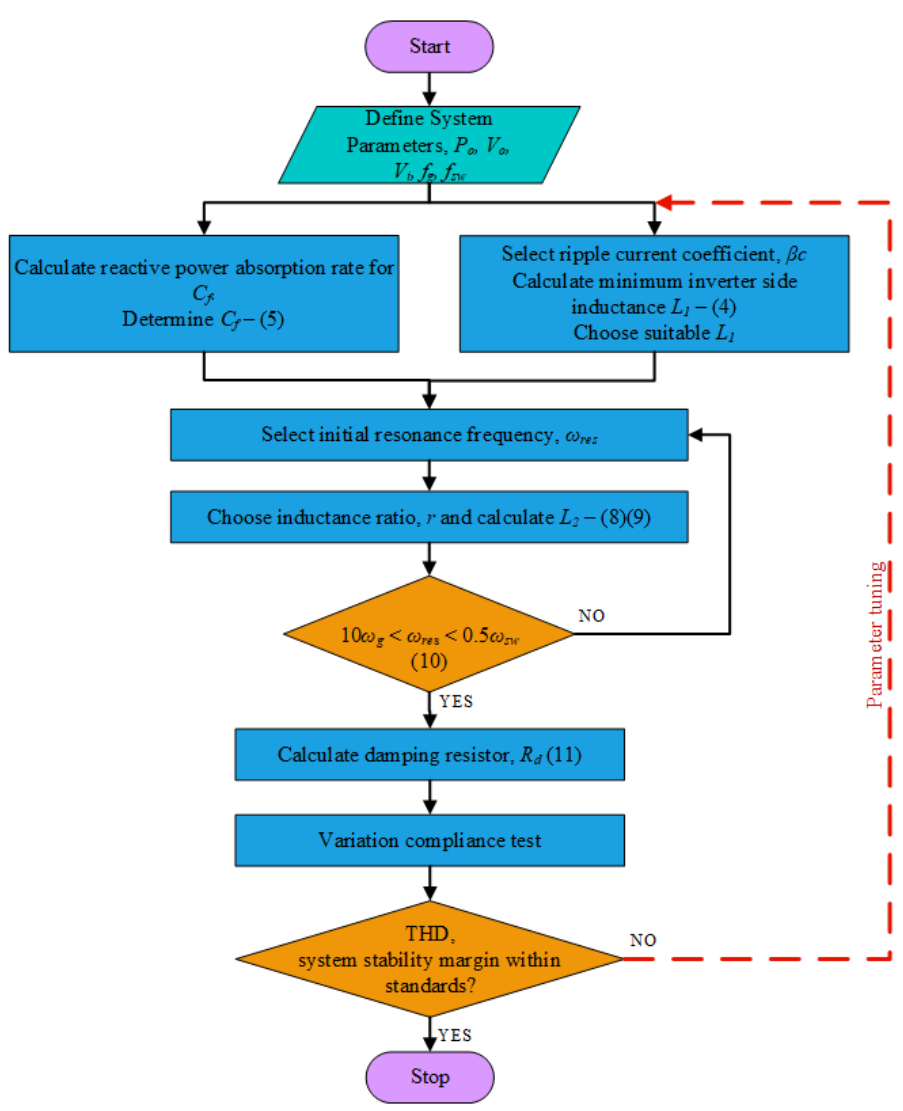

Figure 6: Flowchart of $L C L$ parameter filter design 


\section{SIMULATION}

Simulation of the designed $L C L$ filter is applied to a single-phase grid-connected flyback microinverter was conducted in Matlab/Simulink software based on the circuit shown in Figure 3 . The objective is to verify the proposed calculated passive elements value for the filter and analyze the filter behavior with key component parameters variation. The specification of the designed filter and system are summarized in Table 1 and Table 2. The Bode plot of the designed filter transfer function is plotted in Figure 7. From Figure 7, the system can be seen as stable with 90 degrees and $26.8 \mathrm{~dB}$ of phase margin and gain margin, respectively.

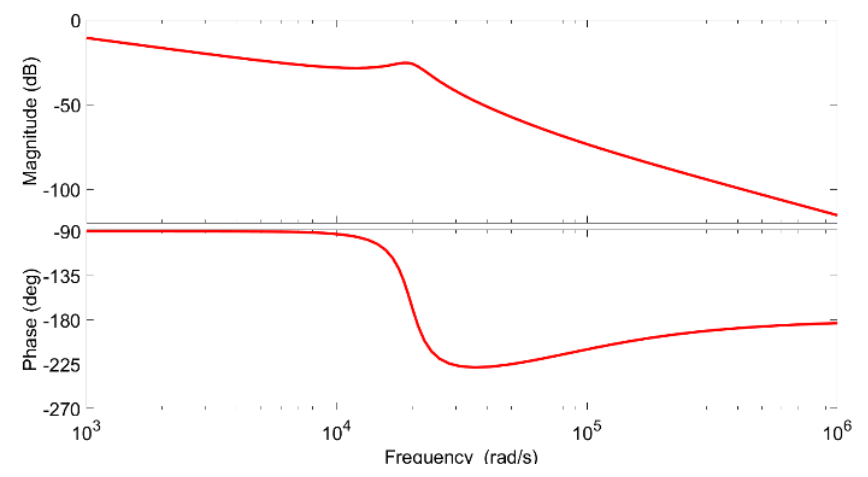

Figure 7: Bode plot of the designed $L C L$ filter based on a parameter in Table 2

The simulation result of the designed filter is shown in Figure 8. Figure 8(a) shows the inverter output voltage and its frequency spectrum upon entering the $L C L$ filter. Figure 8(b) and (c) show the current signal and frequency spectrums for the inverter side inductor and grid side inductor, respectively. The maximum current ripple recorded at the inverter side, $i_{L l}$ is $2 \mathrm{~A}$ and the RMS value of the rated current is 16.6A resulting in the maximum current ripple to rated current ratio equal to $12 \%$. As depicted in Figure 8 (b), the dominant harmonic magnitudes of current $i_{L I}$ appear at $20 \mathrm{kHz}$ and $40 \mathrm{kHz}$ which are $1.8 \%$ and $0.4 \%$ of the fundamental harmonic, respectively, generated from the switching devices. Through the filter, the dominant current harmonic spectrums are successfully suppressed at $i_{L 2}$ as shown in Figure 8(c).

In Figure 9(a), the resonance frequency appears at $63^{\text {rd }}$ harmonic order which is $3.2 \mathrm{kHz}$ as per the initial theoretical calculation. The simulation reveals that the dominant resonance spectrum is $14.74 \%$ from its fundamental component and produced THD at $15.2 \%$ at the output filter point. Eventually, with the implementation of a damping resistor connected in series with a filter capacitor, the resonance frequency generated from the passive element component at the $63^{\text {rd }}$ harmonic is successfully suppressed to $0.14 \%$ with respect to its fundamental component. The significant result can be seen from the plotted frequency spectrum in Figure 9(b).

\section{Impact on parameter variation}

Due to the factors discussed earlier, it is difficult to build a physical filter that precisely fits the theoretical design. These aspects must be taken into account during the design process. An inductance variation in a grid-tied filter could stem from several factors that could be caused by material properties such as core permeability coefficient and manufacturing tolerance. It could also be the result of an inconsistent grid inductance connected in series with $L_{2}$. The capacitance variation in the capacitor due to the manufacturer's tolerance or the aging could also be a contributing factor. Therefore, a simulation on the robustness against the variation is performed to emulate the real case scenario. Six conditions of parameter variations are considered with the assumption that the event happens one at a time

- $30 \%$ increment in $L_{l}$ inductance value.

- $30 \%$ decrement in $L_{l}$ inductance value.

- $30 \%$ increment in $L_{2}$ inductance value.

- $30 \%$ decrement in $L_{2}$ inductance value.

- $20 \%$ increment in $C_{f}$ capacitance value.

- $20 \%$ decrement in $C_{f}$ capacitance value. 
The inductance variation in this paper is set to be $10 \%$ higher compared to other literature [1], [10], [14] to secure a higher system stability margin. The $20 \%$ variation of capacitance is adopted based on the maximum tolerance set by most manufacturers.
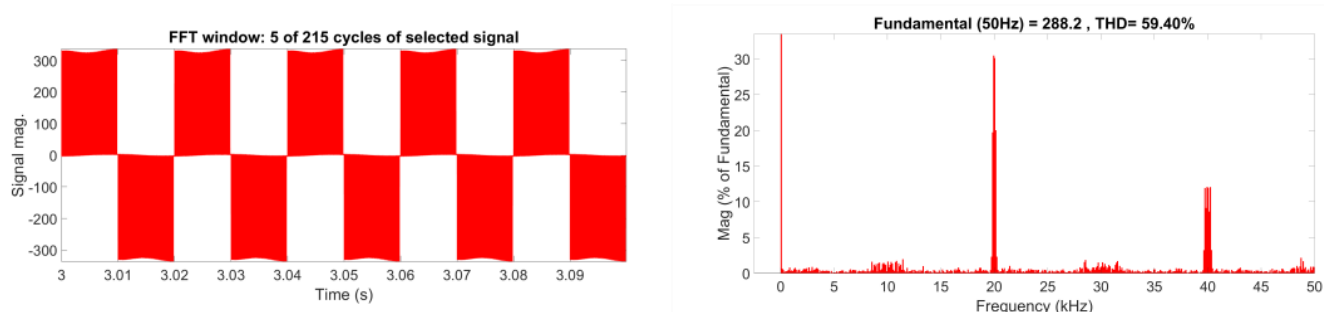

(a)
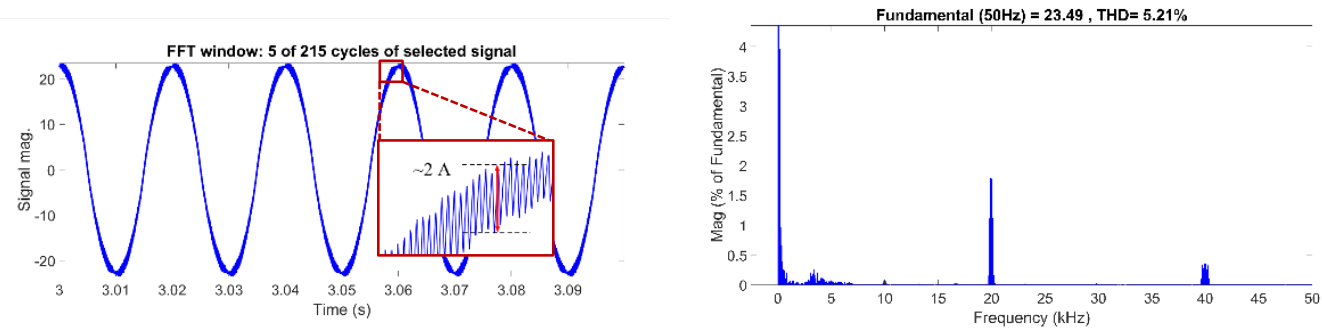

(b)
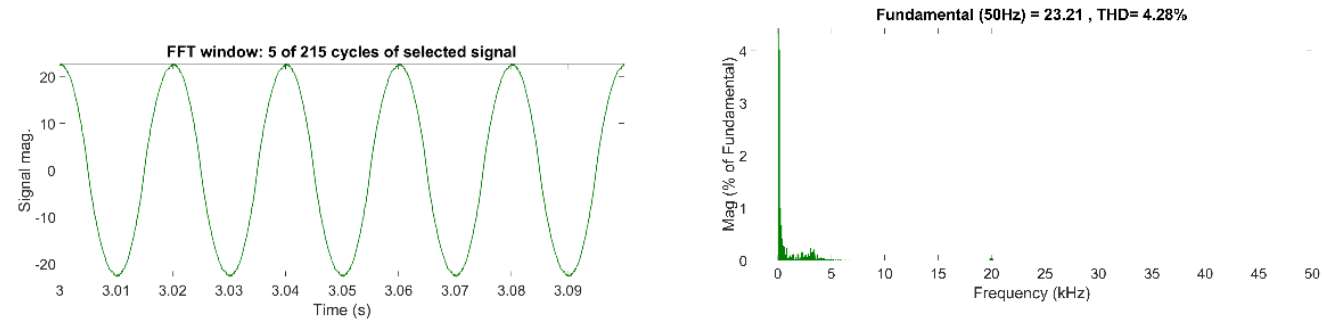

(c)

Figure 8: Simulation result of $L C L$ filter (a) inverter voltage (b) inverter side inductor $i_{L l}$ current, and (c) grid side inductor $i_{L 2}$ current
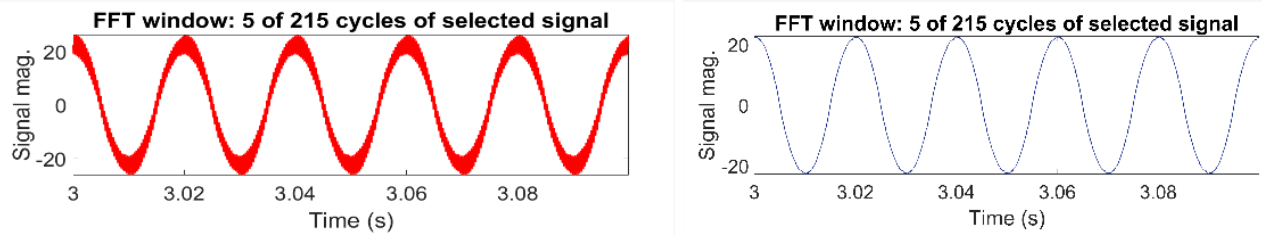

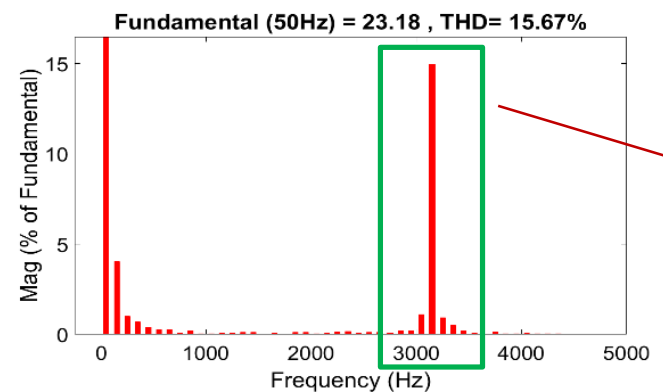

(a)

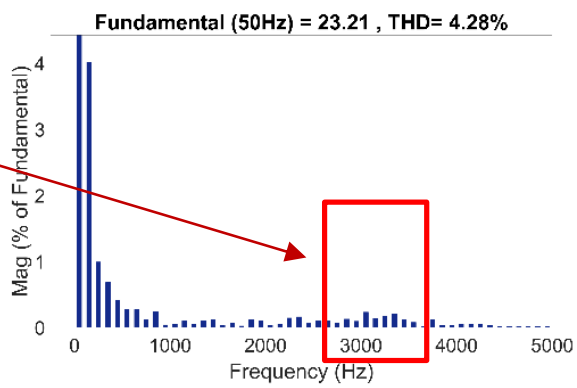

(b)

Figure 9: Signal and spectrum for current: (a)without damping resistor and (b) with a damping resistor 
The simulation result for the first condition is shown in Figure 10(a). The filter showed excellent stability and the ability to absorb the $30 \%$ increment of $L_{l}$. The bode plot shows the gain margin is at $26.9 \mathrm{~dB}$ while the phase margin is at 90 degrees with a slight shift at the system response. Furthermore, the THD value resulted from the event is $3.76 \%$. On the other hand, in the second condition, the decrement of $L_{l}$ by $30 \%$ causes the THD to increase and slightly above the standard threshold limit to $5.01 \%$ as shown in Figure 10(b). However, the system remains stable with a larger gain margin, and with a positive shift from $26.8 \mathrm{~dB}$ to $27.3 \mathrm{~dB}$.

The response from the third condition is shown in Figure 11(a). The rise of $L_{2}$ by $30 \%$ still holds the system at a stable state with $26.9 \mathrm{~dB}$ and 90 degrees gain and phase margin, respectively. The THD value obtained is $3.75 \%$, which is below the standard threshold limit. In contrast, the fourth condition shows when $L_{2}$ decreases, THD increases $0.02 \%$ higher than the standard threshold limit to $5.02 \%$, as shown in Figure 11(b). However, the system stability is maintained at a value $27.3 \mathrm{~dB}$ gain margin and 90 degrees phase margin.

The effect of the filter capacitor variation is illustrated in Figure 12. Figure 12(a) shows the bode plot and frequency spectrum harmonics for the fifth condition. THD value due to the $20 \%$ capacitance rise is measured at $4.29 \%$ and the recorded stability margin is $27 \mathrm{~dB}$ and 90 degrees for the gain and phase, respectively. Similar results were observed in the sixth condition when the capacitance is decreased. The simulation result is illustrated in Figure 12(b). The THD is measured at $4.28 \%$ and the system stability remained at a $26.9 \mathrm{~dB}$ gain margin and 90 degrees phase margin.

Numerical results from parameter variation test simulation as depicted in Figure 10 - Figure 12 under several different cases are summarized in Table 3.

Table 3. The stability margin and THD of the filter with component variations

\begin{tabular}{lccccccc}
\hline & $\begin{array}{c}\text { Initial } \\
\text { component } \\
\text { value }\end{array}$ & $\begin{array}{c}L_{l} \text { increase } \\
30 \%\end{array}$ & $\begin{array}{c}L_{l} \text { decrease } \\
30 \%\end{array}$ & $\begin{array}{c}L_{2} \text { increase } \\
30 \%\end{array}$ & $\begin{array}{c}L_{2} \text { decrease } \\
30 \%\end{array}$ & $\begin{array}{c}C_{f} \text { increase } \\
20 \%\end{array}$ & $\begin{array}{c}C_{f} \text { decrease } \\
20 \%\end{array}$ \\
\hline $\begin{array}{l}\text { Phase } \\
\text { (deg) }\end{array}$ & Margin & 90 & 90 & 90 & 90 & 90 & 90 \\
$\begin{array}{l}\text { Gain } \\
\text { (dB) }\end{array}$ & Margin & 26.8 & 26.9 & 27.3 & 26.9 & 27.3 & 27 \\
THD (\%) & 4.28 & 3.76 & 5.01 & 3.75 & 5.02 & 4.29 \\
\hline
\end{tabular}
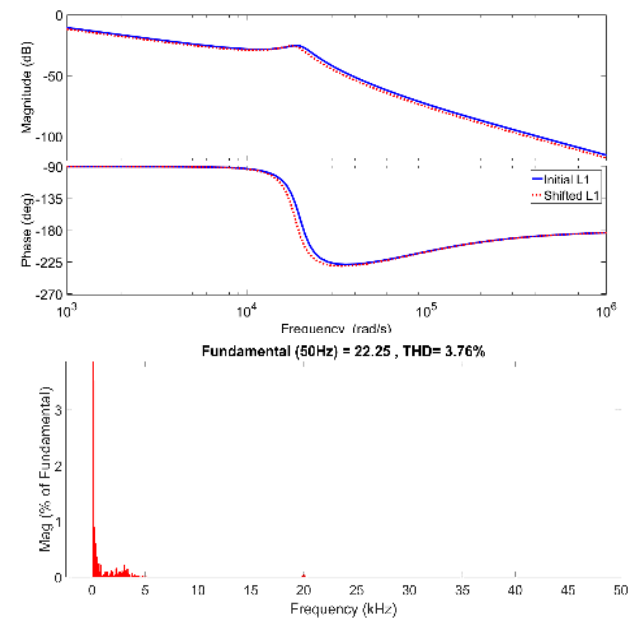

(a)
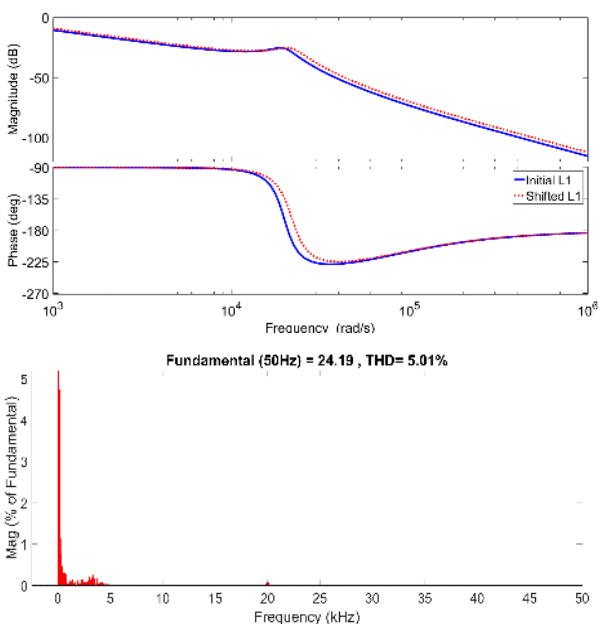

(b)

Figure 10: Frequency spectrum of output filter current and filter bode plot for (a) inductance $L_{l}$ increased by $30 \%$ and (b) inductance $L_{l}$ decreased by $30 \%$ 

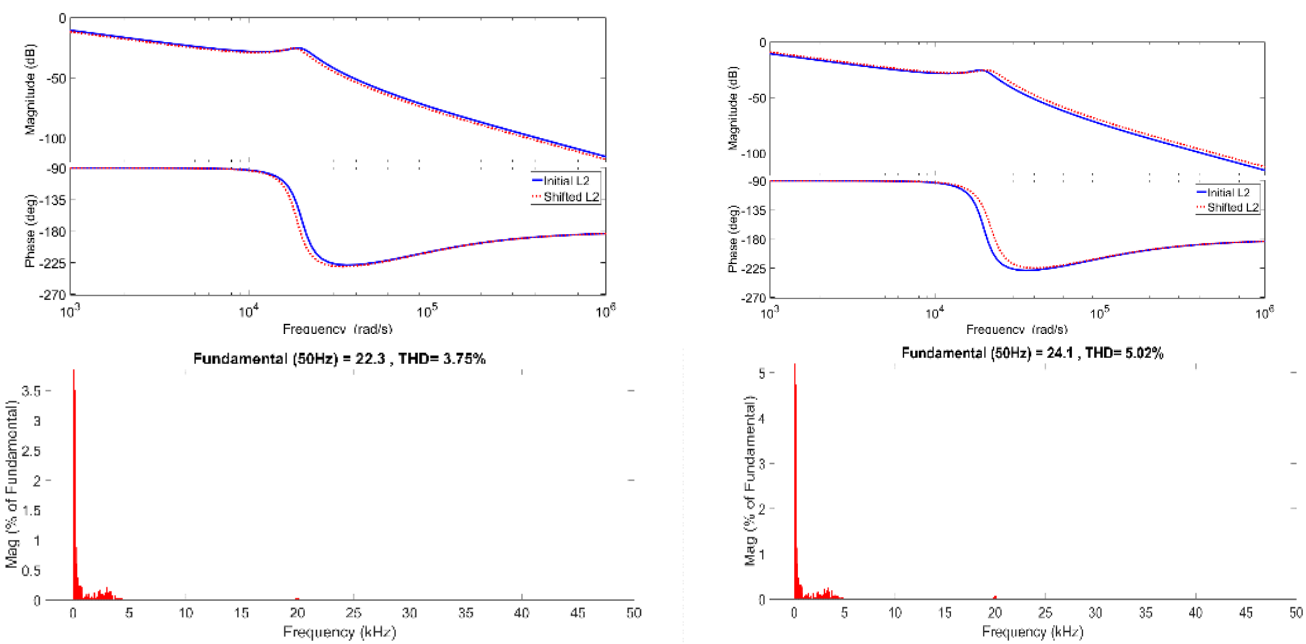

(a)

(b)

Figure 11: Frequency spectrum of output filter current and filter bode plot for (a) inductance $L_{2}$ increased by $30 \%$ and (b) inductance $L_{2}$ decreased by $30 \%$
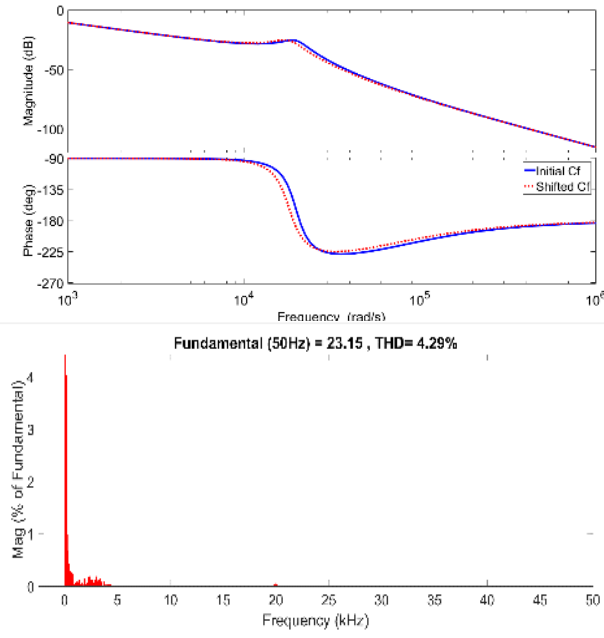

(a)
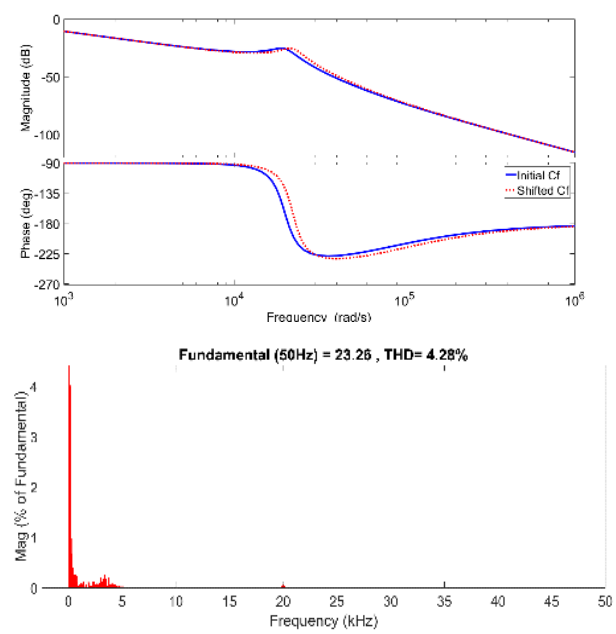

(b)

Figure 12: Frequency spectrum of output filter current and filter bode plot for (a) capacitance $C_{f}$ increased by $20 \%$ and (b) capacitance $C_{f}$ decreased by $20 \%$

\section{CONCLUSION}

This paper has proposed a step-by-step design guideline for the $L C L$ filter used in the gridconnected application, such as flyback microinverter. The $L C L$ filter was designed based on several key aspects to maintain the filter's stability and effectiveness such as maximum current ripple, inductance ratio, and resonance frequency damping. Extensive simulation work was done to validate the theoretical calculation design via Matlab/Simulink. In addition, a detailed analysis on the passive elements' parameter variation is provided in this paper to exhibit its influence on the filter characteristic and performance i.e. stability margin and total harmonic distortion. The proposed design steps produced a filter that remains stable and the THD value is within the international standards (i.e. IEEE1547.1, IEC 60725) despite some parameter variation. However, the analysis reveals that when $r$ is unity, inductor selection must be critically designed because THD value will increase as inductance decrease and it could be worsening if inductance drops beyond $30 \%$ of its designated value. 


\section{ACKNOWLEDGMENTS}

The authors would like to acknowledge the Ministry of Higher Education for financial support via Fundamental Research Grant Scheme FRGS/1/2019/TK07/UPM/02/2. Also, a special thanks to Universiti Teknikal Malaysia Melaka and Universiti Putra Malaysia for their financial and technical support.

\section{REFERENCES}

[1] N. Zhang, H. Tang, and C. Yao, "A systematic method for designing a PR controller and active damping of the LCL filter for single-phase grid-connected PV inverters," Energies, vol. 7, no. 6, pp. 3934-3954, 2014, doi: 10.3390/en7063934.

[2] M. F. Yaakub, M. Amran, M. Radzi, F. Hanim, M. Noh, and M. Azri, "Silicon carbide power device characteristics, applications and challenges : an overview," International Journal of Power Electronics and Drive Systems (IJPEDS), vol. 11, no. 4, pp. 2194-2202, 2020, doi: 10.11591/ijpeds.v11.i4.pp2194-2202.

[3] J. Yin, S. Duan and B. Liu, "Stability analysis of grid-connected inverter with LCL filter adopting a digital singleloop controller with inherent damping characteristic," in IEEE Transactions on Industrial Informatics, vol. 9, no. 2, pp. 1104-1112, May 2013, doi: 10.1109/TII.2012.2222424.

[4] T. Wu, M. Misra, L. Lin, and C. Hsu, "An improved resonant frequency based systematic LCL filter design method for grid-connected inverter," in IEEE Transactions on Industrial Electronics, vol. 64, no. 8, pp. 6412-6421, Aug. 2017, doi: 10.1109/TIE.2017.2682004.

[5] H. Cha, and T.-K. Vu, "Study and design of L-C-L filter for single-phase grid-connected PV inverter," The Korean Institute of Electrical Engineers' Conference, 2009, pp. 23-25.

[6] J. Sedo, and S. Kascak, "Design of output LCL filter and control of single-phase inverter for grid-connected system," in Electrical Engineering, vol. 99, no. 4, pp. 1217-1232, 2017, doi: 10.1007/s00202-017-0617-0.

[7] R. Peña-Alzola, M. Liserre, F. Blaabjerg, R. Sebastián, J. Dannehl, and F. W. Fuchs, "Analysis of the passive damping losses in LCL-filter-based grid converters," in IEEE Transactions on Power Electronics, vol. 28, no. 6, pp. 2642-2646, June 2013, doi: 10.1109/TPEL.2012.2222931.

[8] E. Rodriguez-Diaz, F. D. Freijedo, J. C. Vasquez, and J. M. Guerrero, "Analysis and comparison of notch filter and capacitor voltage feedforward active damping techniques for LCL grid-connected converters," in IEEE Transactions on Power Electronics, vol. 34, no. 4, pp. 3958-3972, April 2019, doi: 10.1109/TPEL.2018.2856634.

[9] F. Mulolani, A. Althobaiti, and Y. Alamoudi, "Notch-filter active damping of LCL filter resonance in a gridconnected inverter with variable grid inductance," 2019 Advances in Science and Engineering Technology International Conferences (ASET), 2019, pp. 1-6, doi: 10.1109/ICASET.2019.8714393.

[10] D. Pan, X. Wang, F. Blaabjerg, and H. Gong, "Active damping of LCL-filter resonance using a digital resonantnotch (biquad) filter," 2018 20th European Conference on Power Electronics and Applications (EPE'18 ECCE Europe), 2018, pp. P.1-P.9.

[11] J. Jo, Z. Liu, and H. Cha, "A new design method of LCL filter for single phase grid connected power converter," 2019 International Symposium on Electrical and Electronics Engineering (ISEE), 2019, pp. 189-193, doi: 10.1109/ISEE2.2019.8921036.

[12] P. Cossoli, M. Cáceres, L. Vera, A. Firman, and A. Busso, "Proportional-resonant controller and LCL filter design for single-phase grid-connected PV micro-inverters," 2018 IEEE PES Transmission \& Distribution Conference and Exhibition - Latin America (T\&D-LA), 2018, pp. 1-5, doi: 10.1109/TDC-LA.2018.8511669.

[13] M. Su et al., "Single-sensor control of LCL-filtered grid-connected inverters," in IEEE Access, vol. 7, pp. 3848138494, 2019, doi: 10.1109/ACCESS.2019.2906239.

[14] IEC publications, "Technical report : consideration of reference impedances and public supply network impedances for use in determining the disturbance characteristics of electrical equipment having a rated Current $\leq 75$ A Per phase foreword," 2005.

[15] "IEEE recommended practice and requirements for harmonic control in electric power systems," in IEEE Std 5192014 (Revision of IEEE Std 519-1992), vol., no., pp.1-29, 11 June 2014, doi: 10.1109/IEEESTD.2014.6826459.

[16] M. Liserre, F. Blaabjerg, and S. Hansen, "Design and control of an LCL-filter-based three-phase active rectifier," in IEEE Transactions on Industry Applications, vol. 41, no. 5, pp. 1281-1291, Sept.-Oct. 2005, doi: 10.1109/TIA.2005.853373.

[17] D. G. Holmes, "A general analytical method for determining the theoretical harmonic components of carrier based PWM strategies," Conference Record of 1998 IEEE Industry Applications Conference. Thirty-Third IAS Annual Meeting (Cat. No.98CH36242), 1998, pp. 1207-1214 vol.2, doi: 10.1109/IAS.1998.730300.

[18] X. Ruan, X. Wang, D. Pan, D. Yang, W. Li, and C. Bao, "Design of LCL filter," in Control Techniques for LCLType Grid-Connected Inverters, Springer, 2018, pp. 31-61.

[19] H. Cha, and T. Vu, "Comparative analysis of low-pass output filter for single-phase grid-connected Photovoltaic inverter," 2010 Twenty-Fifth Annual IEEE Applied Power Electronics Conference and Exposition (APEC), 2010, pp. 1659-1665, doi: 10.1109/APEC.2010.5433454.

[20] Y. Lang, D. Xu, S. R. Hadianamrei, and H. Ma, "A novel design method of LCL type utility interface for threephase voltage source rectifier," 2005 IEEE 36th Power Electronics Specialists Conference, 2005, pp. 313-317, doi: 10.1109/PESC.2005.1581641.

[21] S. Sen, K. Yenduri, and P. Sensarma, "Step-by-step design and control of LCL filter based three phase gridconnected inverter," Proc. IEEE Int. Conf. Ind. Technol., pp. 503-508, 2014, doi: 10.1109/ICIT.2014.6894991. 
[22] M. Liserre, F. Blaabjerg, and A. Dell'aquila, "Step-by-step design procedure for a grid-connected three-phase PWM voltage source converter," International Journal of Electronics, vol. 91, no. 8, pp. 445-460, 2004.

[23] D. Sattianadan, S. Gorai, G. R. Prudhvi Kumar, S. Vidyasagar and V. Shanmugasundaram, "Potency of PR controller for multiple harmonic compensation for a single-phase grid connected system," International Journal of Power Electronics and Drive Systems (IJPEDS), vol. 11, no. 3, pp. 1491-1498, 2020, doi: 10.11591/ijpeds.v11.i3.pp1491-1498.

[24] S.-J. Yoon, T. Van Nguyen and K.-H. Kim, "Current control of grid-connected inverter using integral sliding mode control and resonant compensation," International Journal of Power Electronics and Drive Systems (IJPEDS, vol. 10, no. 2, pp. 1022-1033, 2019, doi: 10.11591/ijpeds.v10.i2.pp1022-1033.

[25] Althobaiti, M. Armstrong, M. A. Elgendy and F. Mulolani, "Three-phase grid connected PV inverters using the proportional resonance controller," 2016 IEEE 16th International Conference on Environment and Electrical Engineering (EEEIC), 2016, pp. 1-6, doi: 10.1109/EEEIC.2016.7555809.

[26] M. Malinowski, M. Jasinski and M. P. Kazmierkowski, "Simple direct power control of three-phase PWM rectifier using space-vector modulation (DPC-SVM)," in IEEE Transactions on Industrial Electronics, vol. 51, no. 2, pp. 447-454, April 2004, doi: 10.1109/TIE.2004.825278.

[27] M. Azab, "Multi-objective design approach of passive filters for single-phase distributed energy grid integration systems using particle swarm optimization," Energy Reports, vol. 6, pp. 157-172, 2020, doi: 10.1016/j.egyr.2019.12.015.

[28] S. Sarajian, "LCL filter design and current control of grid interfaced voltage source inverter," J. Electr. Eng., vol. 15 , no. 1 , pp. 313-324, 2015.

[29] C. C. Gomes, A. F. Cupertino, and H. A. Pereira, "Damping techniques for grid-connected voltage source converters based on LCL filter: An overview," in Renewable and Sustainable Energy Reviews, vol. 81, pp. 116135, 2018, doi: 10.1016/j.rser.2017.07.050.

[30] W. Yao, Y. Yang, X. Zhang and F. Blaabjerg, "Digital notch filter based active damping for LCL filters," 2015 IEEE Applied Power Electronics Conference and Exposition (APEC), 2015, pp. 2399-2406, doi: 10.1109/APEC.2015.7104684.

[31] H. Azani, A. Massoud, L. Benbrahim, B. W. Williams and D. Holiday, "An LCL filter-based grid-interfaced threephase voltage source inverter: Performance evaluation and stability anaylsis," 7th IET International Conference on Power Electronics, Machines and Drives (PEMD 2014), 2014, pp. 1-6, doi: 10.1049/cp.2014.0505. 